\title{
RESEARCH
}

Open Access

\section{Fetal magnetic resonance imaging in the evaluation of congenital diaphragmatic anomalies}

Harshavardhan Mahalingam ${ }^{1 *}$ (D) Biji Babu', Rajeswaran Rangasami ${ }^{1}$, Sudarshan Suresh², Indrani Suresh ${ }^{2}$ and Chitra Andrew ${ }^{3}$

\begin{abstract}
Background: Congenital abnormalities of the diaphragm cause impairment of lung development and are an important cause of post-natal morbidity and mortality. Congenital diaphragmatic eventration (CDE), a less sinister diaphragmatic anomaly compared to the more common congenital diaphragmatic hernia (CDH), often tends to mimic CDH on prenatal imaging. This study evaluates the role of fetal magnetic resonance imaging (MRI) in differentiating these two entities.
\end{abstract}

Results: This was a retrospective study which included fetal MRI studies done in patients with ultrasound diagnosis of fetal diaphragmatic anomaly. MRI exam was performed with a $1.5 \mathrm{~T}$ superconducting system with eight-element torso array coil. The images were studied by two radiologists experienced in fetal imaging in consensus. Diagnosis of CDE was made if the dome of the diaphragm was visualized as a thin hypointense line separating the lung from abdominal structures on coronal and sagittal MRI sequences. If this thin hypointense line was not visualized, a diagnosis of $\mathrm{CDH}$ was made. The findings were then correlated with autopsy/intra-operative findings/post-natal imaging follow-up. A total of 12 patients were included in the study. In these 12 patients, 13 diaphragmatic abnormalities were diagnosed on MRI ( 1 fetus had bilateral diaphragmatic anomaly). Of the 13 diaphragmatic anomalies detected, 7 (54\%) were CDH and 6 (46\%) were CDE. The type of diaphragmatic anomaly was correctly identified on MRI in all except one fetus in which CDE was misdiagnosed as $\mathrm{CDH}$. The Fisher exact test statistic value was 0.0047 . The result was significant at $p<0.01$.

Conclusion: Fetal MRI is a useful tool for assessing congenital diaphragmatic anomalies. Visualization of the diaphragm on coronal and sagittal images helps in diagnosis of complete CDE and differentiating it from the more sinister $\mathrm{CDH}$.

Keywords: Congenital diaphragmatic hernia, Congenital diaphragmatic eventration, Prenatal diagnosis, Fetal MRl, Fetal imaging

\footnotetext{
* Correspondence: harsha.mahalingam@gmail.com

${ }^{1}$ Department of Radiology, Sri Ramachandra Medical College and Research

Institute, No.1, Ramachandra Nagar, Porur, Chennai 600116, India

Full list of author information is available at the end of the article
}

\section{Springer Open}

(c) The Author(s). 2020 Open Access This article is licensed under a Creative Commons Attribution 4.0 International License, which permits use, sharing, adaptation, distribution and reproduction in any medium or format, as long as you give appropriate credit to the original author(s) and the source, provide a link to the Creative Commons licence, and indicate if changes were made. The images or other third party material in this article are included in the article's Creative Commons licence, unless indicated otherwise in a credit line to the material. If material is not included in the article's Creative Commons licence and your intended use is not permitted by statutory regulation or exceeds the permitted use, you will need to obtain permission directly from the copyright holder. To view a copy of this licence, visit http://creativecommons.org/licenses/by/4.0/. 


\section{Background}

The diaphragm is a thin fibromuscular structure which separates the pleural and peritoneal cavities. It develops from four mesodermal elements: the septum transversum, pleuroperitoneal membranes, abdominal wall musculature, and esophageal mesentery [1]. Congenital abnormalities of the diaphragm cause impairment of normal lung development and are an important cause of post-natal morbidity and mortality.

Incidence of congenital diaphragmatic hernia $(\mathrm{CDH})$ is about $1-5$ per 10,000 live births [2]. $\mathrm{CDH}$ is caused by deficient fusion of the pleuroperitoneal membranes and abdominal wall musculature or due to absence of the pleuroperitoneal membranes [3]. The resultant defect in the diaphragm causes displacement of the intraabdominal viscera into the thorax. Nearly $90 \%$ are intrapleural, and most of these are left sided. They cause cardio-mediastinal shift and lung hypoplasia. They are also associated with other major congenital anomaliescardiac, gastrointestinal, and neural tube defects [4]. Congenital diaphragmatic eventration (CDE) is less common than $\mathrm{CDH}$ with reported incidence of 1 in 10,000 live births. It results from incomplete muscularization of the membranous diaphragm with resultant superior displacement of the diaphragm [5]. Unlike $\mathrm{CDH}$, the diaphragm is intact in eventration. Complete eventration more commonly involves the left hemidiaphragm while partial eventration is more common on the right side. In the newborn period, CDE is usually asymptomatic and may be identified during routine check-up. Occasionally, it can be large enough to cause mediastinal shift and pulmonary hypoplasia. It is important to distinguish $\mathrm{CDH}$ from eventration in the antenatal period as the prognosis for $\mathrm{CDH}$ tends to be worse compared to $\mathrm{CDE}$ [6]. Postnatal mortality rates for $\mathrm{CDH}$ are high (around 30-50\%) with pulmonary hypoplasia and pulmonary hypertension being causes of high mortality rate [7]. CDE however does not always require surgical repair and has lower postnatal mortality rate. Accurate antenatal diagnosis of $\mathrm{CDE}$ and ability to confidently differentiate it from the more common $\mathrm{CDH}$ are essential for planning appropriate management and counseling of the parents.

Ultrasonography (USG) is considered the primary imaging modality for antenatal detection of diaphragmatic anomalies. Antenatal USG also plays a role in making volumetric lung measurements which can help predict the outcome of the fetus [8]. However, complete CDE may mimic $\mathrm{CDH}$ on antenatal USG $[9,10]$. In recent times, fetal magnetic resonance imaging (MRI) is being increasingly performed to diagnose and prognosticate these anomalies $[3,11]$. Literature on antenatal diagnosis of CDE is limited to case reports $[6,12-16]$ with no previous studies directly assessing the ability of fetal MRI to differentiate $\mathrm{CDH}$ and $\mathrm{CDE}$. Moreover, the role of fetal MRI in diagnosing CDE is not clearly established in literature. In this retrospective observational study, we assessed the ability of fetal MRI to differentiate these two diaphragmatic anomalies. The objective of the study was to evaluate the role of fetal MRI in differentiating congenital diaphragmatic eventration (CDE) from congenital diaphragmatic hernia (CDH) among fetuses diagnosed to have diaphragmatic anomalies on antenatal USG.

\section{Methods}

This was a retrospective study which included the MRI examinations of patients who were referred to the department of radiodiagnosis of our institute for suspected fetal diaphragm abnormalities from November 2010 to July 2019. We included all patients with suspected fetal diaphragmatic abnormalities based on findings on antenatal USG who subsequently underwent fetal MRI in our institute. USG finding of visualization of intraabdominal contents (like the stomach, small bowel, liver, and spleen) in the thoracic cavity raised suspicion of congenital diaphragmatic anomaly. USG examination however did not differentiate $\mathrm{CDH}$ from $\mathrm{CDE}$ in these patients. Patients who were lost to follow-up following the MRI examination were excluded from the study. The MR imaging studies were identified using keyword search from the department picture archiving and communication system. The MRI examinations were performed with a $1.5 \mathrm{~T}$ superconducting system (Avanto Siemens, Erlangen, Germany) with an eight-element torso array coil. The routine MR sequences obtained in our institution were (1) T2-weighted Half Fourier acquisition single shot turbo spin echo (HASTE) (TR $900 \mathrm{~ms}$, TE 90, FOV 24-28 cm, matrix $256 \times 205$, number of excitations 1 , slice thickness $4.5 \mathrm{~mm}$, intersection gap 0.2 $\mathrm{mm}$ ) and (2) T1-weighted turbo FLASH (TR $100 \mathrm{~ms}$, TE $4.7 \mathrm{~ms}$, flip angle $70^{\circ}$, FOV $24-28 \mathrm{~cm}$, matrix $256 \times 173$, number of excitations 1 , slice thickness $4.5 \mathrm{~mm}$, intersection gap $0.2 \mathrm{~mm}$ ). The images were studied by two radiologists experienced in fetal imaging in consensus. Cases were diagnosed as either $\mathrm{CDH}$ or $\mathrm{CDE}$ based on visualization of the ipsilateral dome of the diaphragm as a thin hypointense line separating the lung from abdominal structures on coronal and sagittal images. The following findings were also recorded: laterality (right/left/ bilateral), nature of abdominal contents displaced into the thoracic cavity (stomach, small bowel, large bowel, spleen, and/or liver), and observed/expected lung area to head circumference ratio expressed as percentage (LHR). LHR was calculated by multiplying transverse and anteroposterior dimensions of the contralateral lung at level of the four-chamber view of the heart and dividing the result by the head circumference. This value was 
then compared to age-matched controls using a nomogram provided by Peralta et al. [17]. The MRI findings were then correlated with autopsy (in case of medical termination of pregnancy or post-natal demise)/intraoperative findings or post-natal imaging follow-up (in patients treated conservatively).

\section{Results}

A total of 12 patients were included in our study. A flow chart of the study outline and results is presented in Fig. 1 . Age of the patients included in the study ranged from 22 to 33 years with mean of 24.5 years. Four $(33.3 \%)$ of the patients were primigravida, and $8(66.6 \%)$ were multigravida. None of the patients had any history of fetal anomalies in previous pregnancies. Gestational age of patients at time of MRI examination ranged from 21 to 31 weeks with mean of 23.2 weeks. Out of the 12 patients assessed, $8(66.7 \%)$ patients presented in the 2nd trimester, and $4(33.3 \%)$ patients presented in the 3rd trimester. No patients presented in the 1st trimester. Fetal echocardiography performed prior to MRI did not reveal any associated intra-cardiac anomalies. Tests for detection of chromosomal anomalies were not available for any of the cases. In these 12 patients, 13 diaphragmatic abnormalities were diagnosed on MRI (1 fetus had bilateral diaphragmatic anomaly). We did not compare the MRI diagnosis with that of USG as detailed USG data were not available. These pregnant women had USG elsewhere and were referred to our center for fetal MRI.

The normal fetal diaphragm is visualized on MRI as a thin curvilinear low signal intensity structure separating the thoracic and abdominal cavities on T2-weighted coronal and sagittal images (Fig. 2). Based on the visualization of this $\mathrm{T} 2$ hypointense line, cases were diagnosed as either $\mathrm{CDH}$ (no hypointense line present between the thoracic and abdominal contents) or $\mathrm{CDE}$ (hypointense line present between the thoracic and abdominal contents). Examples of cases of $\mathrm{CDE}$ and $\mathrm{CDH}$ are presented in Figs. 3 and 4 respectively.

Of the 13 anomaly studies diagnosed on MRI, 8 were diagnosed as $\mathrm{CDH}$ (including one fetus with bilateral $\mathrm{CDH}$ ), and 5 were diagnosed as CDE. Majority of the diaphragmatic anomalies $(11 / 13,84.6 \%)$ were on the left side. Stomach was the commonest content of herniation (seen in all left-sided diaphragmatic anomalies) followed by small bowel (69\%).

Based on post-natal follow-up or autopsy, the final diagnosis made was CDH in 7 out of 13 anomalies (54\%) and CDE in 6 out of 13 anomalies (46\%). Mean LHR

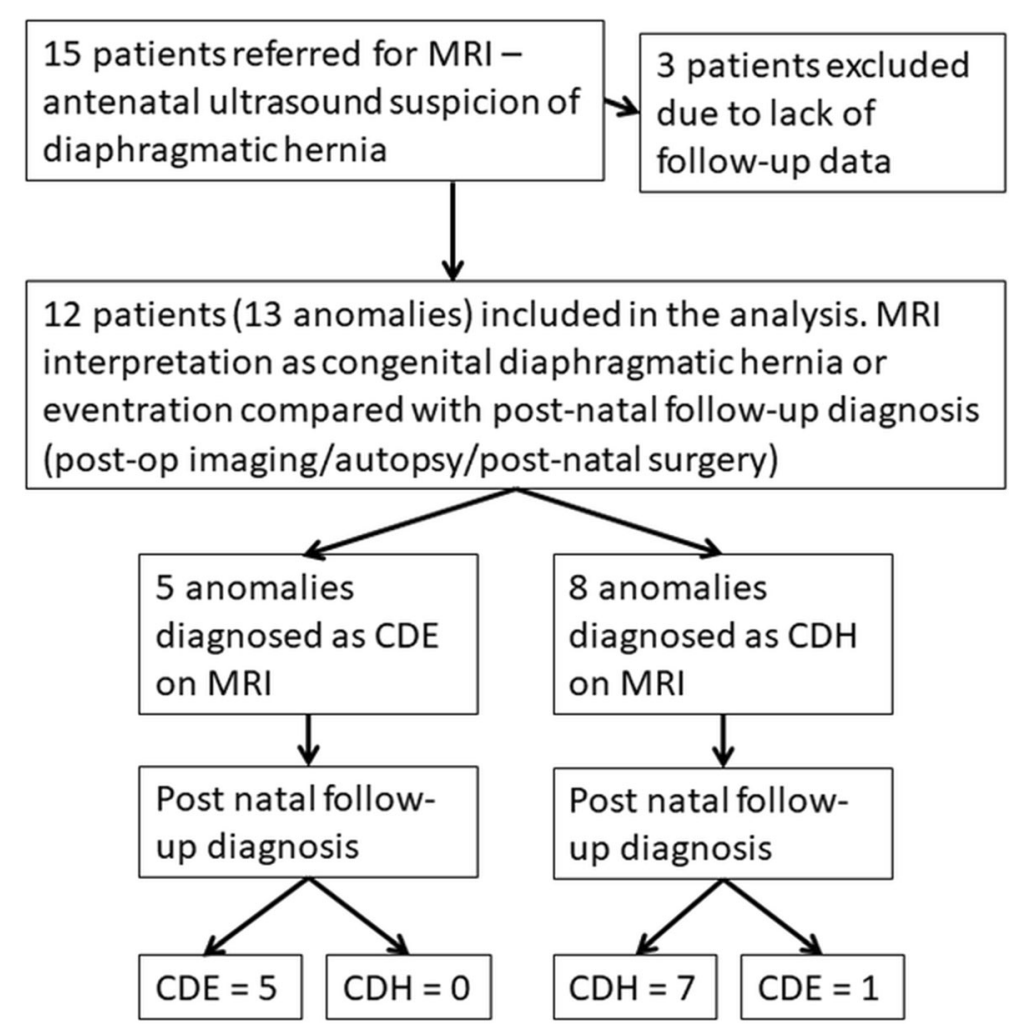

Fig. 1 Flow chart representing the study outline and results. $\mathrm{CDE}$, congenital diaphragmatic eventration; $\mathrm{CDH}$, congenital diaphragmatic hernia; MRI, magnetic resonance imaging 

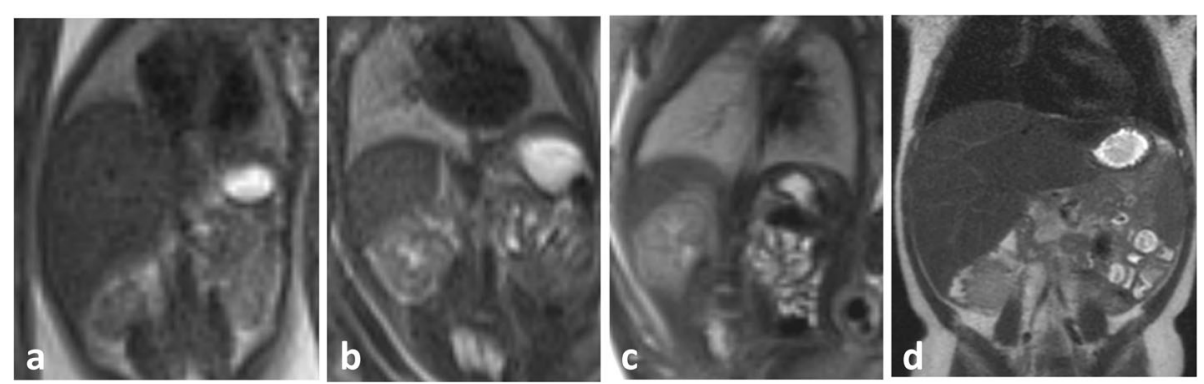

Fig. 2 Selected images of coronal T2-weighted MRI showing the appearance of normal diaphragm (arrows) at 21, 29, and 33 weeks of gestation and in a newborn (a, b, c and $\mathbf{d}$ respectively)

was $42.1 \%$ in $\mathrm{CDH}$ group $(\mathrm{SD}=21.9)$ and $33.1 \%$ in CDE group $(\mathrm{SD}=14.2)$. Out of the 6 patients identified to have $\mathrm{CDH}, 4$ neonates died immediately after delivery and 2 neonates survived and were operated. These two infants were doing well at 2 months follow-up. Out of the 6 patients identified to have eventration, 2 underwent medical termination of pregnancy, 1 neonate died immediately after delivery, and 3 infants survived after delivery. Of these three, one was operated and is doing well on follow-up while the other two were managed conservatively. The mean LHR of all cases of diaphragmatic anomaly with postnatal demise was $31.3 \%$, and mean LHR in infants alive at 2 months follow-up was $51.2 \%$. There was a statistically significant difference in between these two groups $(p<0.05)$. The demographic details, imaging findings, and postnatal follow-up details of patients included in the study are provided in Table 1.

The type of diaphragmatic anomaly was correctly identified in all except one patient in whom CDE was misdiagnosed as $\mathrm{CDH}$. The Fisher exact test statistic value was 0.0047 . The result was significant at $p<0.01$.

\section{Discussion}

The goal of prenatal imaging in congenital anomalies of the diaphragm is to establish the diagnosis and to identify prognostic features which can help in management and counseling. Prenatal USG is the primary imaging modality. The diagnosis of both $\mathrm{CDH}$ and $\mathrm{CDE}$ is done by observing abdominal viscera within the thoracic cavity. Ancillary findings are mediastinal shift to the opposite side, small abdominal circumference, observing peristalsis within the thoracic cavity, and polyhydramnios.

Accurate prenatal imaging diagnosis of congenital diaphragmatic anomalies is dependent on various factors like gestational age at presentation, size, and side of the diaphragmatic anomaly. The earlier the gestation, the more difficult it is to diagnose these anomalies. Many of these anomalies are detected in the late second trimester or in the third trimester. Establishing a diagnosis of CDH before 24 weeks of gestational age is difficult [18]. Prenatal USG detection of right-sided diaphragmatic anomalies is lower than left because of similar echogenicity of the liver and the lung. The displaced liver in the

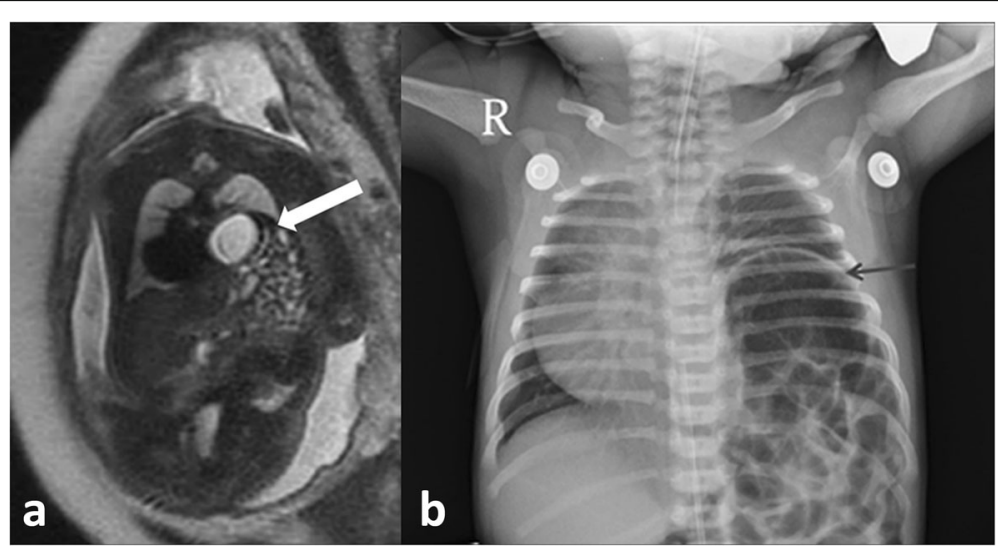

Fig. 3 Thirty-three-year-old G2 P1 L1 at 32 weeks of gestation with features of left-sided eventration. a Coronal T2-weighted MRI image of fetal trunk showing the presence of stomach and small and large bowel loops in the thoracic cavity with an intact diaphragm (white arrow). $\mathbf{b}$ Postnatal chest radiograph showing elevated left hemidiaphragm (black arrow) outlined by the lung superiorly and bowel gasses inferiorly 


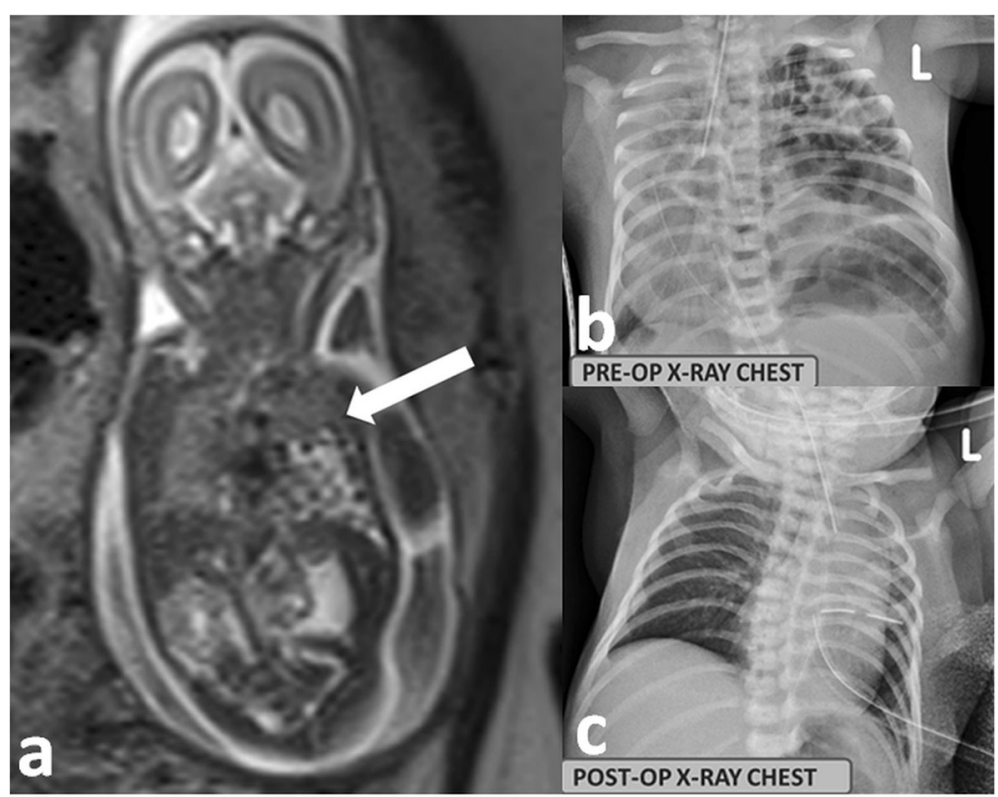

Fig. 4 Twenty-eight-year-old G2 P1 L1 at 21 weeks of gestation with features of left-sided diaphragmatic hernia. a Coronal T2-weighted MRI image of the fetal trunk showing the presence of stomach and small and large bowel loops in the thoracic cavity (arrow) with no discernible hypointense line between the left lung and abdominal viscera. b Postnatal chest radiograph taken on the 1st day of life showing multiple bowel loops in the left hemithorax with complete mediastinal shift to the right side. Endotracheal tube is noted in situ in the trachea which is deviated to the right side. The baby underwent diaphragm repair surgery. c Post-operative chest radiograph showing normal position of both domes of diaphragm with endotracheal tube and left intercostal drainage tube in situ

Table 1 Demography, imaging findings, postnatal outcome, and follow-up details of patients with fetal diaphragmatic anomalies included in the study

\begin{tabular}{|c|c|c|c|c|c|c|c|}
\hline $\begin{array}{l}\text { S. } \\
\text { no. }\end{array}$ & $\begin{array}{l}\text { Gestational age at } \\
\text { diagnosis (weeks) }\end{array}$ & Herniated contents & $\begin{array}{l}\text { Laterality of the } \\
\text { diaphragmatic anomaly }\end{array}$ & LHR (\%) & $\begin{array}{l}\text { MRI } \\
\text { diagnosis }\end{array}$ & $\begin{array}{l}\text { Final } \\
\text { diagnosis }\end{array}$ & Outcome \\
\hline 1 & 31 & $\begin{array}{l}\text { Stomach, small and } \\
\text { large bowel }\end{array}$ & Left & 22.4 & $\mathrm{CDH}$ & $\mathrm{CDH}$ & $\begin{array}{l}\text { Died immediately after } \\
\text { birth }\end{array}$ \\
\hline 2 & 30 & $\begin{array}{l}\text { Stomach, small and } \\
\text { large bowel }\end{array}$ & Left & 18.4 & $\mathrm{CDH}$ & $\mathrm{CDH}$ & $\begin{array}{l}\text { Died immediately after } \\
\text { birth }\end{array}$ \\
\hline 3 & 22 & $\begin{array}{l}\text { Stomach, part of liver, } \\
\text { small and large bowel }\end{array}$ & Bilateral & $\begin{array}{l}\text { Not } \\
\text { calculated }\end{array}$ & $\mathrm{CDH}$ & $\mathrm{CDH}$ & $\begin{array}{l}\text { Died immediately after } \\
\text { birth }\end{array}$ \\
\hline 4 & 21 & $\begin{array}{l}\text { Stomach, part of liver, } \\
\text { and small bowel }\end{array}$ & Left & 42.5 & $\mathrm{CDH}$ & $\mathrm{CDH}$ & $\begin{array}{l}\text { Died immediately after } \\
\text { birth }\end{array}$ \\
\hline 5 & 24 & Stomach, part of liver & Left & 42 & CDE & $\mathrm{CDE}$ & Died 1 month after surgery \\
\hline 6 & 24 & Liver & Right & 15.5 & $\mathrm{CDE}$ & $\mathrm{CDE}$ & TOP \\
\hline 7 & 21 & $\begin{array}{l}\text { Stomach and part } \\
\text { of liver }\end{array}$ & Left & 34.5 & CDE & CDE & Operated, doing well \\
\hline 8 & 32 & $\begin{array}{l}\text { Stomach, small and } \\
\text { large bowel }\end{array}$ & Left & 41.6 & $\mathrm{CDH}$ & CDE & $\begin{array}{l}\text { Conservative management, } \\
\text { doing well }\end{array}$ \\
\hline 9 & 24 & $\begin{array}{l}\text { Stomach and small } \\
\text { bowel. }\end{array}$ & Left & 13 & CDE & $\mathrm{CDE}$ & TOP \\
\hline 10 & 21 & $\begin{array}{l}\text { Stomach, small and } \\
\text { large bowel }\end{array}$ & Left & 79.8 & $\mathrm{CDH}$ & $\mathrm{CDH}$ & Operated, doing well \\
\hline 11 & 29 & $\begin{array}{l}\text { Stomach, small and } \\
\text { large bowel }\end{array}$ & Left & 48 & $\mathrm{CDH}$ & $\mathrm{CDH}$ & Operated, doing well \\
\hline 12 & 21 & $\begin{array}{l}\text { Stomach, part of liver, } \\
\text { small and large bowel }\end{array}$ & Left & 52 & CDE & CDE & $\begin{array}{l}\text { Conservative management, } \\
\text { doing well }\end{array}$ \\
\hline
\end{tabular}

$C D E$ congenital diaphragmatic eventration, $C D H$ congenital diaphragmatic hernia, LHR lung head ratio (observed LHR/expected LHR $\times 100$ ) expressed as percentage, TOP termination of pregnancy 
thoracic cavity can be misinterpreted as the lung thus resulting in a missed diagnosis. Around $10-25 \%$ of cases can be missed on antenatal screening USG $[19,20]$. The main advantages of MRI over USG in this scenario are its ability to provide a three-dimensional visualization of the diaphragm irrespective of fetal position and maternal habitus and its better prognostic potential [21].

The fetal lung being primarily composed of water has a uniformly bright signal on T2-weighted MR images. The diaphragm is hypointense on T2-weighted images and can be identified as a thin hypointense line separating the thoracic and abdominal cavities on coronal and sagittal images. In our study, the diaphragm was clearly delineated in all cases of CDE except one. In this case (patient 8 in Table 1), the diaphragm could not be delineated, and hence, this was misdiagnosed as $\mathrm{CDH}$. This was likely related to suboptimal image quality as a result of excessive fetal movements during MRI. The ipsilateral dome of the diaphragm was not visible in any of the cases finally diagnosed as CDH. The mean LHR was significantly lower in cases of post-natal demise compared to infants surviving to 2 months of age (including cases of both $\mathrm{CDH}$ and CDE). While MRI-based LHR is well established as a prognostic marker in $\mathrm{CDH}$ [22], our study suggests that it can be used as prognostic marker even in cases of CDE.

Literature on prenatal diagnosis of $\mathrm{CDE}$ and its differentiation from $\mathrm{CDH}$ is limited. Jeanty et al. [23] have documented that presence of pleural or pericardial effusions favor diagnosis of $\mathrm{CDE}$ over $\mathrm{CDH}$. In our study, none of the fetuses had pleural or pericardial effusion, and hence, this finding could not be utilized in the diagnosis. Karmazyn et al. [24] have shown that presence of a folding free muscle edge and narrow angle waist favored diagnosis of $\mathrm{CDH}$ over $\mathrm{CDE}$ in postnatal period although this differentiation was not possible in around one-third of their cases. The findings of their study cannot be directly compared with our study because they had evaluated diaphragmatic defects in infants after birth and not in prenatal period. No previous studies have assessed the role of fetal MRI in differentiating $\mathrm{CDE}$ from $\mathrm{CDH}$. In this context, our study has shown it is possible to confidently differentiate these two conditions in antenatal period using fetal MRI.

Limitations of our study are its retrospective nature and small sample size. However, CDE is an uncommon anomaly and multicenter studies can be undertaken for including larger number of patients. We did not include data on genetic/chromosomal studies of the fetuses as it was not available. We did not perform dynamic imaging to assess movement of the fetal diaphragm. We did not compare the accuracy of MRI with that of USG.

\section{Conclusion}

We have demonstrated in our study that fetal MRI is a useful tool for imaging the fetal diaphragm. Fetal MRI can consistently demonstrate the elevated hemidiaphragm in cases of CDE. Visualization of the diaphragm on coronal and sagittal images helps in differentiating CDE from the more sinister $\mathrm{CDH}$. Future prospective studies with larger sample size are required to assess the impact of differentiating $\mathrm{CDE}$ and $\mathrm{CDH}$ during antenatal period on fetal and postnatal management.

\section{Abbreviations}

CDE: Congenital diaphragmatic eventration; $\mathrm{CDH}$ : Congenital diaphragmatic hernia; FLASH: Fast low angle shot; FOV: Field of view; HASTE: Half Fourier acquisition single shot turbo spin echo; LHR: Lung area head circumference ratio; MRI: Magnetic resonance imaging; USG: Ultrasonography

\section{Acknowledgements}

Not applicable

\section{Authors' contributions}

$\mathrm{BB}$ and RR collected the patient data. HM and RR analyzed and interpreted the patient data. HM prepared the manuscript. RR, SS, IS, and CA edited the manuscript. All authors read and approved the final manuscript.

\section{Funding}

No external funding was obtained for this study

Availability of data and materials

All data generated or analyzed during this study are included in this article (Table 1 presents the data collected for purpose of this study).

Ethics approval and consent to participate

This study was performed in line with the principles of the Declaration of Helsinki. Approval was granted by the Ethics Committee of Sri Ramachandra University with IEC number NI/20/FEB/74/25

\section{Consent for publication}

No separate individual consent was obtained from patients for this study as it was retrospective in nature, and the examinations were carried out as part of routine clinical care. No patient-identifying information is included in the manuscript material.

\section{Competing interests}

None

\section{Author details}

'Department of Radiology, Sri Ramachandra Medical College and Research Institute, No.1, Ramachandra Nagar, Porur, Chennai 600116, India. ${ }^{2}$ Mediscan Systems, Chennai 600005, India. ${ }^{3}$ Department of Obstetrics and Gynaecology, Sri Ramachandra Medical College and Research Institute, Porur, Chennai 600116, India.

Received: 29 July 2020 Accepted: 21 October 2020

Published online: 05 November 2020

\section{References}

1. Chiu PPL, Langer JC (2009) Surgical conditions of the diaphragm: posterior diaphragmatic hernias in infants. Thorac Surg Clin 19:451-461. https://doi. org/10.1016/j.thorsurg.2009.08.009

2. Tovar JA (2012) Congenital diaphragmatic hernia. Orphanet J Rare Dis 7:1. https://doi.org/10.1186/1750-1172-7-1

3. Mehollin-Ray AR, Cassady Cl, Cass DL, Olutoye $\mathrm{OO}$ (2012) Fetal MR imaging of congenital diaphragmatic hernia. RadioGraphics 32:1067-1084. https:// doi.org/10.1148/rg.324115155

4. Brownlee EM, Howatson AG, Davis CF, Sabharwal AJ (2009) The hidden mortality of congenital diaphragmatic hernia: a 20-year review. J Pediatr Surg 44:317-320. https://doi.org/10.1016/j.jpedsurg.2008.10.076

5. Al-Salem AH (2014) Eventration of the diaphragm. In: An illustrated guide to pediatric surgery. Springer, Cham, pp 345-349 
6. Jurcak-Zaleski S, Comstock CH, Kirk JS (1990) Eventration of the diaphragm Prenatal diagnosis. J Ultrasound Med 9:351-354. https://doi.org/10.7863/ jum.1990.9.6.351

7. Oliver ER, DeBari SE, Adams SE, Didier RA, Horii SC, Victoria T, Hedrick HL, Adzick NS, Howell LJ, Moldenhauer JS, Coleman BG (2019) Congenital diaphragmatic hernia sacs: prenatal imaging and associated postnatal outcomes. Pediatr Radiol 49:593-599. https://doi.org/10.1007/s00247-01804334-9

8. Alamo L, Gudinchet F, Meuli R (2015) Imaging findings in fetal diaphragmatic abnormalities. Pediatr Radiol 45:1887-1900. https://doi.org/ 10.1007/s00247-015-3418-5

9. Yang Jl (2003) Left diaphragmatic eventration diagnosed as congenital diaphragmatic hernia by prenatal sonography. J Clin Ultrasound 31:214-217. https://doi.org/10.1002/jcu.10157

10. Bishara J, Burjonrappa S, Pirzada M, Halaby C, Bishara J, Burjonrappa S, Pirzada M, Halaby C (2015) Diaphragmatic eventration misdiagnosed as diaphragmatic hernia in a preterm infant with respiratory distress: a case report and review of diagnosis and management. Open J Pediatr Child Health 1:001-004

11. Rajeswaran R, Chandrasekharan A, Joseph S, Venkata Sai PM, Dev B, Reddy S (2009) Ultrasound versus MRI in the diagnosis of fetal head and trunk anomalies. J Matern Fetal Neonatal Med 22:115-123. https://doi.org/10. 1080/14767050802488238

12. Iskender C, Tarım E, Yalcınkaya C (2012) Prenatal diagnosis of right diaphragmatic eventration associated with fetal hydrops. J Obstet Gynaecol Res 38:858-862. https://doi.org/10.1111/j.1447-0756.2011.01831.x

13. Tsukahara Y, Ohno Y, Itakura A, Mizutani S (2001) Prenatal diagnosis of congenital diaphragmatic eventration by magnetic resonance imaging. Am J Perinatol 18:241-244

14. Sahinoglu Z, Yuksel A, Uludogan M, Bilgic R, Toksoy G (2011) Left diaphragmatic eventration associated with ipsilateral pulmonary sequestration and intrathoracic kidney in a fetus: reviewing the prenatal diagnosis and etiopathogenesis. Fetal Pediatr Pathol 30:233-243. https://doi. org/10.3109/15513815.2011.555808

15. Hasegawa T, Imura K, Kubota A, Kobayashi T, Inoue M, Hata S, Shimizu I, Suehara N (1994) Congenital diaphragmatic eventration detected by antenatal ultrasound: rationale for early operation. Pediatr Surg Int 9:405406. https://doi.org/10.1007/BF01686016

16. Cheng H (2018) EP06.20: prenatal diagnosis of fetal diaphragmatic eventration, mimicking diaphragmatic hernia. Ultrasound Obstet Gynecol 52:216-216. https://doi.org/10.1002/uog.19865

17. Peralta CFA, Cavoretto P, Csapo B, Vandecruys H, Nicolaides KH (2005) Assessment of lung area in normal fetuses at 12-32 weeks. Ultrasound Obstet Gynecol 26:718-724. https://doi.org/10.1002/uog.2651

18. Grisaru-Granovsky S, Rabinowitz R, loscovich A, Elstein D, Schimmel MS (2009) Congenital diaphragmatic hernia: review of the literature in reflection of unresolved dilemmas. Acta Paediatr 98:1874-1881. https://doi.org/10. 1111/j.1651-2227.2009.01436.x

19. Gallot D, Coste K, Francannet C, Laurichesse H, Boda C, Ughetto S, Vanlieferinghen P, Scheye T, Vendittelli F, Labbe A, Dechelotte PJ, Sapin V, Lemery D (2006) Antenatal detection and impact on outcome of congenital diaphragmatic hernia: a 12-year experience in Auvergne, France. Eur J Obstet Gynecol Reprod Biol 125:202-205. https://doi.org/10.1016/j.ejogrb. 2005.06.030

20. Huddy CL, Boyd PA, Wilkinson AR, Chamberlain P (1999) Congenital diaphragmatic hernia: prenatal diagnosis, outcome and continuing morbidity in survivors. BJOG Int J Obstet Gynaecol 106:1192-1196. https:// doi.org/10.1111/j.1471-0528.1999.tb08147.x

21. Bebbington M, Victoria T, Danzer E, Moldenhauer J, Khalek N, Johnson M, Hedrick H, Adzick NS (2014) Comparison of ultrasound and magnetic resonance imaging parameters in predicting survival in isolated left-sided congenital diaphragmatic hernia. Ultrasound Obstet Gynecol 43:670-674. https://doi.org/10.1002/uog.13271

22. Kilian AK, Schaible T, Hofmann V, Brade J, Neff KW, Büsing KA (2009) Congenital diaphragmatic hernia: predictive value of MRI relative lung-tohead ratio compared with MRI fetal lung volume and sonographic lung-tohead ratio. Am J Roentgenol 192:153-158. https://doi.org/10.2214/AJR.08. 1082

23. Jeanty C, Nien J, Espinoza J, Kusanovic J, Goncalves L, Qureshi F, Jacques S, Lee W, Romero R (2007) Pleural and pericardial effusion: a potential ultrasonographic marker for the prenatal differential diagnosis between congenital diaphragmatic eventration and congenital diaphragmatic hernia. Ultrasound Obstet Gynecol 29:378-387. https://doi.org/10.1002/uog.3958

24. Karmazyn B, Shold AJ, Delaney LR, Brown BP, Marine MB, Jennings SG, Gray BW (2019) Ultrasound evaluation of right diaphragmatic eventration and hernia. Pediatr Radiol 49:1010-1017. https://doi.org/10.1007/s00247-01904417-1

\section{Publisher's Note}

Springer Nature remains neutral with regard to jurisdictional claims in published maps and institutional affiliations.

\section{Submit your manuscript to a SpringerOpen ${ }^{\circ}$ journal and benefit from:}

- Convenient online submission

- Rigorous peer review

- Open access: articles freely available online

- High visibility within the field

- Retaining the copyright to your article

Submit your next manuscript at $\boldsymbol{\nabla}$ springeropen.com 